\title{
Molecular approaches to the taxonomic position of Peruvian potato cyst nematodes and gene pool similarities in indigenous and imported populations of Globodera
}

\author{
ERIC GRENIER*, MICHEL BOSSIS, DIDIER FOUVILLE, LIONEL RENAULT \\ \& DIDIER MUGNIÉRY \\ UMR INRA/ENSAR Biologie des Organismes et des Populations appliquée à la Protection des Plantes, \\ Domaine de la Motte, BP 35327, 35653 Le Rheu cedex France
}

\begin{abstract}
Peruvian potato cyst nematode populations were analysed to assess both their inter- and intraspecific similarities. ITS-RFLP and two satellite DNA sequences were used as taxonomic tools. Both techniques have confirmed that the Peruvian populations have as their closest relatives the European Globodera pallida, despite the detection of clear differences that prevents us from assigning these South American populations unambiguously to any Globodera species. A more precise study of the variability of these Peruvian populations was investigated and they were compared with the imported European populations using protein (2-DGE) and DNA (RAPD) datasets. The clear distinction between the Peruvian and the European populations was confirmed and, inside each group, no correlation was found between the pathotype classification and the observed clustering of the populations. Surprisingly, while RAPDs revealed a higher variability in the Peruvian group than in the European one, some characteristic proteins were found by 2-DGE in some European populations, whereas it was impossible to find any in the Peruvian populations. It is concluded that the primary founders of the European populations may have an origin other than that of the Peruvian populations involved in this study.
\end{abstract}

Keywords: DNA fingerprinting, Globodera spp., imported populations, protein electrophoresis, species determination, tandem repeat sequence.

\section{Introduction}

The potato cyst nematodes (PCN) Globodera rostochiensis and G. pallida are thought to have originated in the Andean region of South America (Evans \& Stone, 1977) and to have been introduced into Europe after 1850 (Evans et al., 1975). They are major pests of potato, causing significant economic losses. Plant resistance is an effective means to control PCN, but its wide application is hampered by the occurrence of various virulent nematode populations. Determining whether there has been more than one introduction has practical importance for the management of these pests, since the genetic basis of virulence may differ.

PCNs are classified into pathotypes on the basis of their ability to multiply on different potato clones. However, the status of their pathotypes is still a matter of debate (Phillips \& Trudgill, 1983; Mugniéry et al.,

*Correspondence. E-mail: grenier@rennes.inra.fr
1989). The International Pathotype Scheme introduced by Kort et al. (1977) recognizes, among the European populations, five pathotypes within G. rostochiensis and three within $G$. pallida, while the Latin American Scheme (Canto \& Scurrah, 1977) recognizes among the South American populations of these two species four and seven pathotypes, respectively. As outlined by Bakker et al. (1993), these schemes are not able to reflect all of the genetic diversity introduced into Europe.

Biochemical and molecular characterizations of PCN populations have been conducted to relate the genetic diversity to the virulence and to find markers that readily distinguish the pathotypes (Folkertsma et al., 1996b; Blok et al., 1997; Thiéry et al., 1997). Except to a certain degree for G. rostochiensis, no clear correlation has been found between the groupings obtained using various molecular techniques and the virulence. Moreover, some South American populations of G. pallida tend to form a 
distinct group, separate from the European G. pallida (Blok et al., 1997; Bendezu et al., 1998).

The objectives of this research were to look first at the taxonomic relationships among Globodera species. Following the work of Thiéry \& Mugniéry (1996), a complementary study of the polymorphism of the rDNA Internal Transcribed Spacer (ITS) was conducted on the Peruvian populations. Highly repetitive satellite DNAs were also isolated and used as species-specific markers. Then, two-dimensional gel electrophoresis (2-DGE) of proteins and Random Amplified Polymorphic DNA (RAPD) techniques were used to produce two independent but complementary datasets for the assessment of the intraspecific genetic variation among both indigenous (Peruvian) and imported (European) populations identified as $G$. pallida.

\section{Materials and methods}

\section{Nematode populations, genomic DNA and total soluble protein preparations}

All the populations (Table 1) came from our laboratory collection and were reared on their common host. DNA

\begin{tabular}{|c|c|c|c|c|}
\hline Species & \multicolumn{2}{|c|}{ Origin of populations } & Pathotype & Code \\
\hline G. artemisiae & & Germany & & \\
\hline G. rostochiensis & Ecosse & Great Britain & Ro1 & Eco \\
\hline G.t. tabacum & Agen & France & & Age \\
\hline G.t. virginiae & & USA & & GV1 \\
\hline G.t. solanacearum & & USA & & GS1 \\
\hline G. mexicana & Santa Ana & Mexico & & Ana \\
\hline G. pallida & & Germany & $\mathrm{Pa} 2 / 3$ & BB1 \\
\hline G. pallida & & Germany & $\mathrm{Pa} 2 / 3$ & BB2 \\
\hline G. pallida & Noirmoutier & France & $\mathrm{Pa} 2 / 3$ & Noi \\
\hline G. pallida & Lanslebourg & France & $\mathrm{Pa} 2 / 3$ & Lan \\
\hline G. pallida & Audierne & France & $\mathrm{Pa} 2 / 3$ & Aud \\
\hline G. pallida & Perpignan & France & $\mathrm{Pa} 2 / 3$ & Per \\
\hline G. pallida & Pas de Calais & France & $\mathrm{Pa} 2 / 3$ & $P d c$ \\
\hline G. pallida & Guiclan & France & $\mathrm{Pa} 2 / 3$ & Gui \\
\hline G. pallida & Saint Malo & France & $\mathrm{Pa} 2 / 3$ & Sma \\
\hline G. pallida & Lufness & Great Britain & $\mathrm{Pa} 2 / 3$ & Luf \\
\hline G. pallida & Bedale & Great Britain & $\mathrm{Pa} 2 / 3$ & Bed \\
\hline G. pallida & Duddingston & Great Britain & Pa1 & Dud \\
\hline G. pallida & Chavornay & Switzerland & $\mathrm{Pa} 2 / 3$ & Cha \\
\hline G. pallida & Mase & Switzerland & $\mathrm{Pa} 2 / 3$ & Mas \\
\hline G. pallida & Pukekoe & New Zealand & $\mathrm{Pa} 2$ & Puk \\
\hline G. pallida & & Peru & P4A & P4A \\
\hline G. pallida & & Peru & $\mathrm{P} 4 \mathrm{~A}$ & P4A 1 \\
\hline G. pallida & & Peru & $\mathrm{P} 4 \mathrm{~A}$ & P4A 2 \\
\hline G. pallida & & Peru & P4A & P4A 3 \\
\hline G. pallida & & Peru & P4A & P4A 4 \\
\hline G. pallida & & Peru & P4A & P4A 5 \\
\hline G. pallida & & Peru & $\mathrm{P} 4 \mathrm{~A}$ & P4A 6 \\
\hline G. pallida & Chocon & Peru & P4A & P4A Cho \\
\hline G. pallida & & Peru & P5A & P5A \\
\hline G. pallida & & Peru & P5A & P5A 7 \\
\hline G. pallida & & Peru & P5A & P5A 8 \\
\hline G. pallida & & Peru & P5A & P5A 10 \\
\hline G. pallida & & Peru & P5A & P5A 12 \\
\hline G. pallida & Otuzco & Peru & P5A & P5A Otu \\
\hline G. pallida & & Peru & P6A & P6A \\
\hline G. pallida & & Peru & P6A & P6A 13 \\
\hline G. pallida & & Peru & P6A & P6A 14 \\
\hline G. pallida & & Peru & P6A & P6A 15 \\
\hline G. pallida & & Peru & P6A & P6A 18 \\
\hline G. pallida & Huamacucho & Peru & P6A & P6A Hua \\
\hline
\end{tabular}

Table 1 Names and related codes of the Globodera populations tested. The origins and the pathotype classification of each population are indicated when known. Pathotype determination was usually made by the institute which had sent us the population (i.e. CIP Lima, SCRI Dundee and BBA Münster) 
was extracted from frozen females ground in liquid nitrogen by a phenol/chloroform procedure followed by ethanol precipitation as described in Thiéry \& Mugniéry (1996). The proteins were extracted as described in Bossis \& Mugniéry (1993) and stored at $-70^{\circ} \mathrm{C}$. DNA and protein extractions were carried out, respectively, on 2500 and 100 females per sample and the average yields were $10 \mu \mathrm{g}$ of DNA and $150 \mu \mathrm{g}$ of protein per sample.

\section{Cloning and sequencing of the satellite DNAs}

Two micrograms of genomic DNA from $G$. pallida Guiclan and P6A populations were digested to completion with the SmaI and AluI restriction enzymes (Boehringer Mannheim), respectively. The smallest fragments $(\approx 200 \mathrm{bp})$ visualized following agarose gel electrophoresis were first recovered onto DEAE paper (Sambrook et al., 1989) and then cloned into pUC 18 plasmid (Pharmacia). The ligation mixture was used to transform the competent Escherichia coli strain JM109 (Promega). The sequencing of the inserts selected after cloning was performed on an ABI Prism 310 automated sequencer (PE Applied Biosystems). The consensus sequences appear in the EMBL and GenBank databases under the accession numbers AF250033 and AF250034 for the SmaI and AluI satellite DNAs, respectively.

\section{Dot blot procedure}

Dot blots were prepared by denaturing $100 \mathrm{ng}$ of genomic DNA of each population with $2 \mathrm{M} \mathrm{NaOH}$ for $10 \mathrm{~min}$, and neutralizing it with ammonium acetate $4 \mathrm{M}$. Whole samples were then dotted by vacuum onto nitrocellulose membranes (Amersham) in a dot blotting apparatus (Bio-Rad).

\section{ITS amplification and restriction procedures}

ITS-RFLP analyses were performed as described by Thiéry \& Mugniéry (1996). Primers were the same as those described in Vrain et al. (1992) and PCR conditions were 30 cycles of a denaturation step at $94^{\circ} \mathrm{C}$ for $1 \mathrm{~min}$, annealing at $60^{\circ} \mathrm{C}$ for $50 \mathrm{~s}$ and extension at $72^{\circ} \mathrm{C}$ for $1 \mathrm{~min}$. A final extension was performed at the end for $5 \mathrm{~min}$ at $72^{\circ} \mathrm{C}$. The amplified products were digested to completion with a set of 16 restriction enzymes (Table 2). Digestion products were separated by electrophoresis in a $1.5 \%$ agarose gel and visualized by ethidium bromide staining.

\section{RAPD procedure}

PCR reactions were performed as described by Thiéry et al. (1997) in a final volume of $12.5 \mu \mathrm{L}$, using eight random primers from the kits $\mathrm{G}$ and $\mathrm{L}$ of Operon Technologies (USA). Genomic DNA (15 ng per reaction) was first denatured by heating at $94^{\circ} \mathrm{C}$ for $5 \mathrm{~min}$ and then processed through 40 cycles, each consisting of $1.0 \mathrm{~min}$ at $94^{\circ} \mathrm{C}, 1.0 \mathrm{~min}$ at $35^{\circ} \mathrm{C}$ and $1.0 \mathrm{~min}$ at $72^{\circ} \mathrm{C}$. A final extension was performed at the end for $5 \mathrm{~min}$ at $72^{\circ} \mathrm{C}$. PCR products were visualized by ethidium bromide staining on agarose gels after electrophoresis. Three replicates of each amplification were performed independently and a negative control was always included as a test for contamination. A population marker was chosen if it was present without ambiguity in the three repeated amplification reactions. Differences in band intensity were not a consideration.

\section{Two-dimensional gel electrophoresis}

2-DGE analyses were carried out with the mini Protean II equipment (Bio-Rad) mainly following O'Farrell's procedure (O'Farrell, 1975). Modifications included the use of PDA as crosslinker and of ammonium thiosulphate as a reducer of the background (Hochstrasser et al., 1988). Staining was obtained with ammoniacal silver solution (Oakley et al., 1980) with slight modifications (Bossis \& Mugniéry, 1993). Molecular weights and isoelectric points were determined with the 2D SDS-PAGE standards (Bio-Rad), consisting of six reduced denatured proteins: hen egg white conalbumin, bovine serum albumin, bovine muscle actin, bovine carbonic anhydrase, soybean trypsin inhibitor and equine myoglobin.

\section{Analysis of protein patterns}

Images of gels were compared on a Vax station 4000-60 computer (Digital Equipment Corporation) with the Kepler software (Large Scale Biology Corporation, Rockville, USA). Gels were digitized $(2048 \times 2048$ elements) with a scanner (Eikonix EC78/99, Kodak) at a resolution of $100 \mu \mathrm{m} /$ pixel. From each image file a fitted spotfile was generated and used as the basic data in all the analysis. This step was run with the procbille process (Zivy, 1990). Each protein spot encoded by a master number (MSN) was characterized by its coordinates $(\mathrm{x}, \mathrm{y})$, its width (sx, sy) and its amplitude (amp). The amplitude is dependent on the optical density of the elements of each spot. The volume (vol) of each modelled spot was calculated according to vol. $=2 \cdot \pi \cdot \mathrm{sx} \cdot \mathrm{sy} \cdot \mathrm{amp}$.

Triplicates of protein samples were prepared from each population. Whatever its volume, a spot was considered to be present in a population when it was detected in at least two of the three gels of this population. A synthetic pattern called the master was built including the spots analysed in all the populations. Then, the matching was initiated in an interactive approach using 40 spots 


\begin{tabular}{lccl}
\hline Enzyme & $\begin{array}{c}\text { Number of } \\
\text { markers revealed }\end{array}$ & Polymorphism & $\begin{array}{c}\text { Digestion pattern type } \\
\text { like that of the Peruvian }\end{array}$ \\
\hline AluI & 5 & Yes & GR, GT, GM and GP \\
BglI & 3 & No & None \\
Bsh1236 I & 10 & Yes & GA, GR and GT \\
Bsp143 I & 6 & Yes & GA, GT, GM and GP \\
DdeI & 4 & Yes & GR, GT, GM and GP \\
HaeIII & 3 & Yes & GT, GM and GP $\left(^{*}\right)$ \\
HhaI & 8 & Yes & \\
HincII & 2 & No & GM and GP \\
HinfI & 4 & Yes & GM and GP $\left.*^{*}\right)$ \\
ItaI & 7 & Yes & GR and GM \\
MaeII & 7 & Yes & GM and GP $\left.*^{*}\right)$ \\
MaeIII & 12 & Yes & GA, GR and GT \\
NdeII & 6 & Yes & \\
PstI & 2 & No & GR and GT \\
RsaI & 6 & Yes & None \\
TaqI & 7 & Yes & \\
\hline
\end{tabular}

Table 2 Restriction enzymes used in the ITS-RFLP analysis of the Peruvian populations and digestion pattern comparison of the Peruvian with different Globodera species. GA, GR, GT, GM and GP stand for G. artemisiae, G. rostochiensis, G. tabacum, 'G. mexicana' and European G. pallida, respectively. Presence of an asterisk (*) means that some Peruvian populations have produced other digestion pattern types than the ones mentioned selected as the easiest to match. On this basis, automatic matching was performed and all the combinations were studied using logical operations, so that shared proteins were identified for each pair of populations.

\section{Cluster analysis}

Polymorphic markers were recorded as a binary matrix corresponding to their absence or presence. The genetic distances were estimated on the basis of the Nei similarity index (Nei, 1972) and trees were obtained with the Neighbour Joining algorithm using the PHYLIP software (Felsenstein, 1993) with the bootstrap and consensus tree options.

\section{Results}

\section{Comparison of the ITS restriction fragment length polymorphisms}

The amplified ITS of all the Globodera species and populations tested was $1200 \mathrm{bp}$. More than 90 markers were revealed after digestion of the ITS (Table 2). Only 44 were used in the cluster analysis of Fig. 1 as some were not polymorphic (BglI, HincII and PstI), or others, when summed, resulted in a much higher size than the expected $1200 \mathrm{bp}$ due to additional digestion of some markers. As expected, G. artemisiae - as representative of the Compositae Globodera species - is distant from the Solanaceae Globodera species. 'G. mexicana' and the European $G$. pallida are extremely close, whereas G. rostochiensis and G. tabacum are more distinct. The Peruvian G. pallida split into three groups without clear correlation with their pathotypes. These three groups are closely related to each other and to a lesser extent to

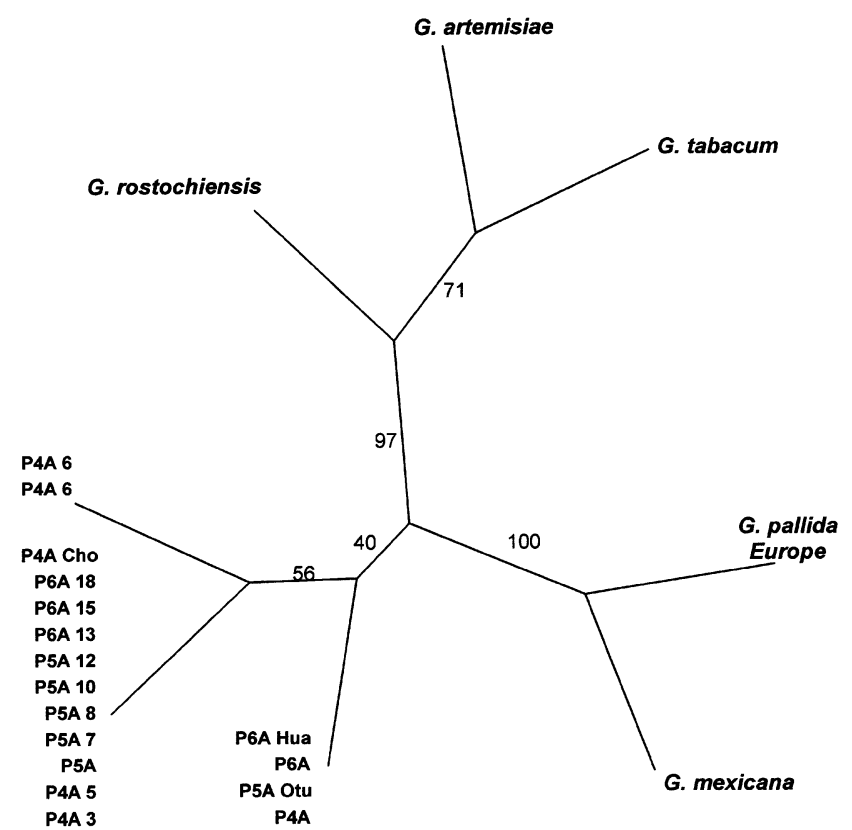

Fig. 1 Unrooted boot-strapped tree of Globodera species and of the Peruvian populations inferred by Neighbour Joining from the ITS-RFLP data. Bootstrap values are indicated besides each branch and were obtained after 500 iterations.

the 'G. mexicana' and European G. pallida cluster. The Peruvian populations are separated from the European G. pallida, however, the bootstrap values are quite low.

\section{Isolation and primary structure of two satellite DNA families}

Digestion of genomic DNA from the G. pallida Guiclan and P6A populations has revealed intensely staining 


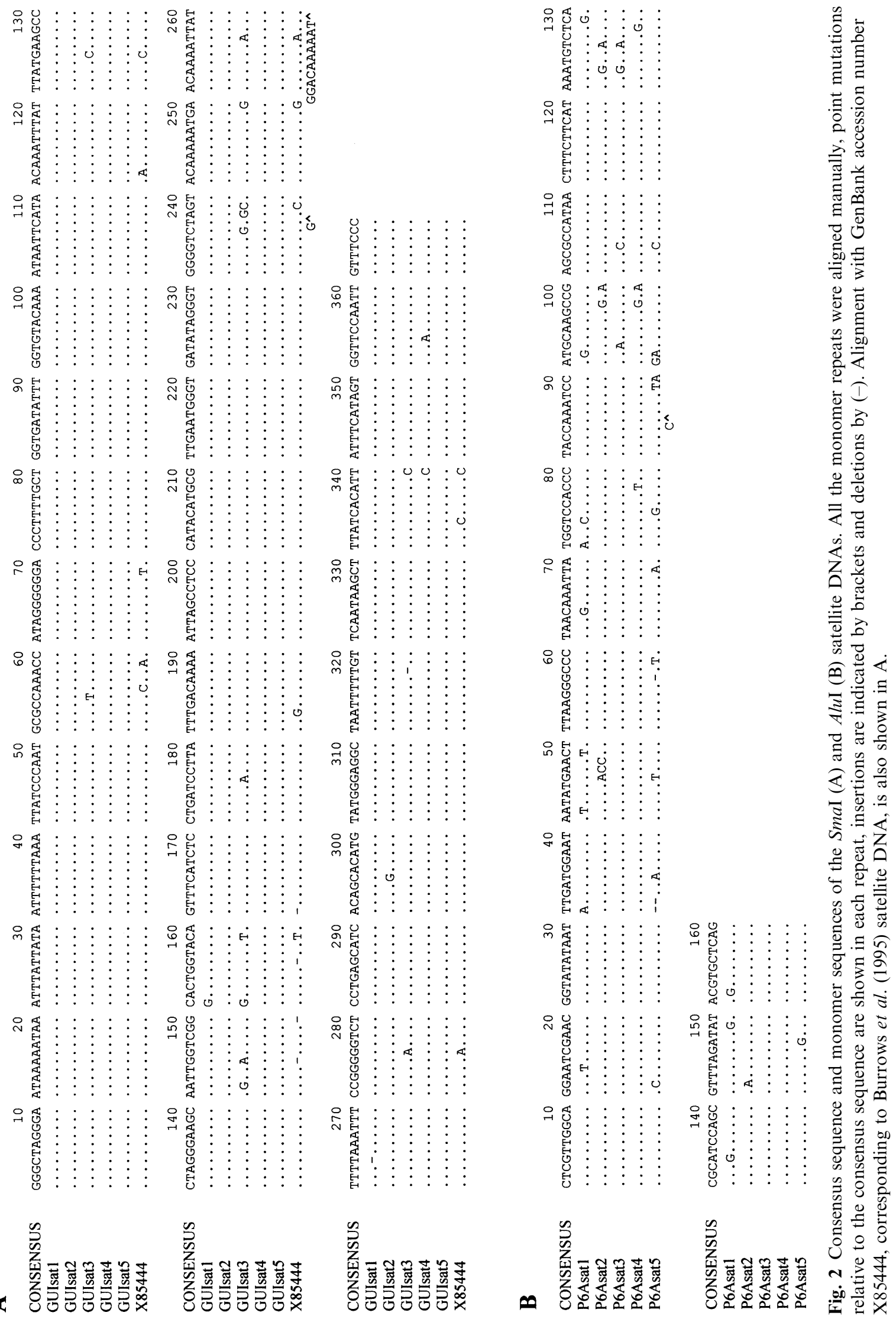

(C) The Genetics Society of Great Britain, Heredity, 86, 277-290. 
bands of approximately $350 \mathrm{bp}$ and $150 \mathrm{bp}$ in, respectively, the SmaI digest of Guiclan and the $A l u \mathrm{I}$ digest of P6A. After cloning, 10 suitable clones displaying an insert of the expected size (five of $350 \mathrm{bp}$ and five of $150 \mathrm{bp}$ ) were selected for further analysis. Unambiguous consensus sequences of $367 \mathrm{bp}$ and $160 \mathrm{bp}$ were deduced from the alignment of the SmaI and AluI fragments, respectively (Fig. 2).

The SmaI and AluI satellite DNA families have an adenine + thymine content of $63 \%$ and $58 \%$, respectively. The five monomers cloned in each of these families differ mainly by single base substitutions, but two- and three-point deletions plus one insertion are found in the SmaI and $A l u \mathrm{I}$ satellite DNA families, respectively. Sequence variation among the cloned monomers of each family relative to the derived consensus sequence is quite low, ranging from 0 to 15 variant nucleotides per cloned repeat for the $S m a$ I satellite DNA family and 4 to 16 for the $A l u \mathrm{I}$ satellite DNA family. The average divergences from the consensus sequence for these two satellite DNA families are $1.7 \%$ and $5.5 \%$, respectively.

No significant similarity was detected between these two satellite DNA families (only $31 \%$ DNA identity). Comparison with other sequences recorded in the GenBank and EMBL databases revealed no substantial similarities in the case of the AluI satellite DNA family, but $94 \%$ of DNA identity with a repetitive element of G. pallida (GenBank accession number X85444) in the case of the SmaI satellite DNA family.

\section{Species-specificity of the isolated satellite DNA sequences}

The $S m a \mathrm{I}$ and $A l u \mathrm{I}$ repeated elements were hybridized to genomic DNA of various Globodera populations. Figure 3A indicates that the SmaI satellite DNA isolated from Guiclan hybridizes strongly with the European populations of $G$. pallida but more weakly with the Peruvian ones. Hybridization was never detected with genomic DNA of $G$. rostochiensis and ' $G$. mexicana' even with long exposure times, but a slight signal was consistently observed with a subset of the G. tabacum populations classified as G. t. virginiae.

The AluI satellite DNA isolated from P6A hybridized equally with the European and Peruvian populations of G. pallida (Fig. 3B), but a signal was also clearly observed with the closely related species 'G. mexicana'. With longer exposure times, hybridization signals were even observed with G. rostochiensis and G. $t$. virginiae.

\section{Two-dimensional gel electrophoresis of proteins}

On the master, 542 spots were scored including the very faint ones (vol. < 500). A mean of 286 spots per
$\mathbf{A}$

B

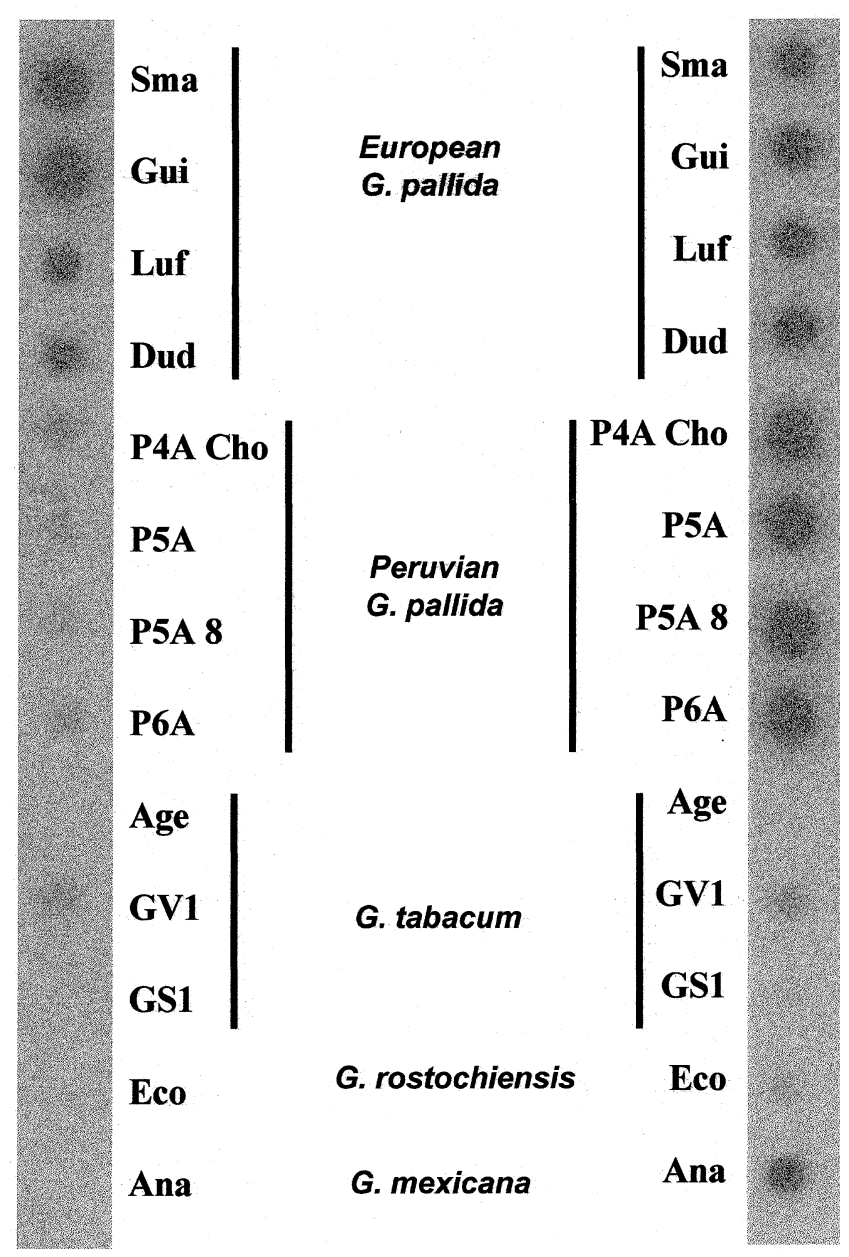

Fig. 3 Species-specificity of the isolated satellite DNA sequences. Genomic DNAs of populations of different Globodera species were dot blotted onto a membrane and hybridized with the SmaI (A) or AluI (B) satellite DNAs.

population was detected. Figure 4 gives the master on which all spots are displayed and where some of them (in dark) are identified by their MSN as in Table 3.

Some of these discriminating spots were characteristic of only one population and could be used as markers for these populations: MSNs 537 for Audierne, 565 for Luffness, 582 for Pukekoe and 502 for P6A. The absence of one spot can also be used in the identification of five populations: MSNs 42 and 409 for Luffness, 62 for Duddingston, 218 for Perpignan, 254 for Chavornay and 322 for Pukekoe. Of the 18 spots strongly represented in the European populations, three (MSNs 531, 535 and 541) were never observed in the Peruvians. But, among the 19 spots strongly represented in the Peruvian populations, none were absent from the Europeans (Table 3). However, MSN 453, which was never detec- 


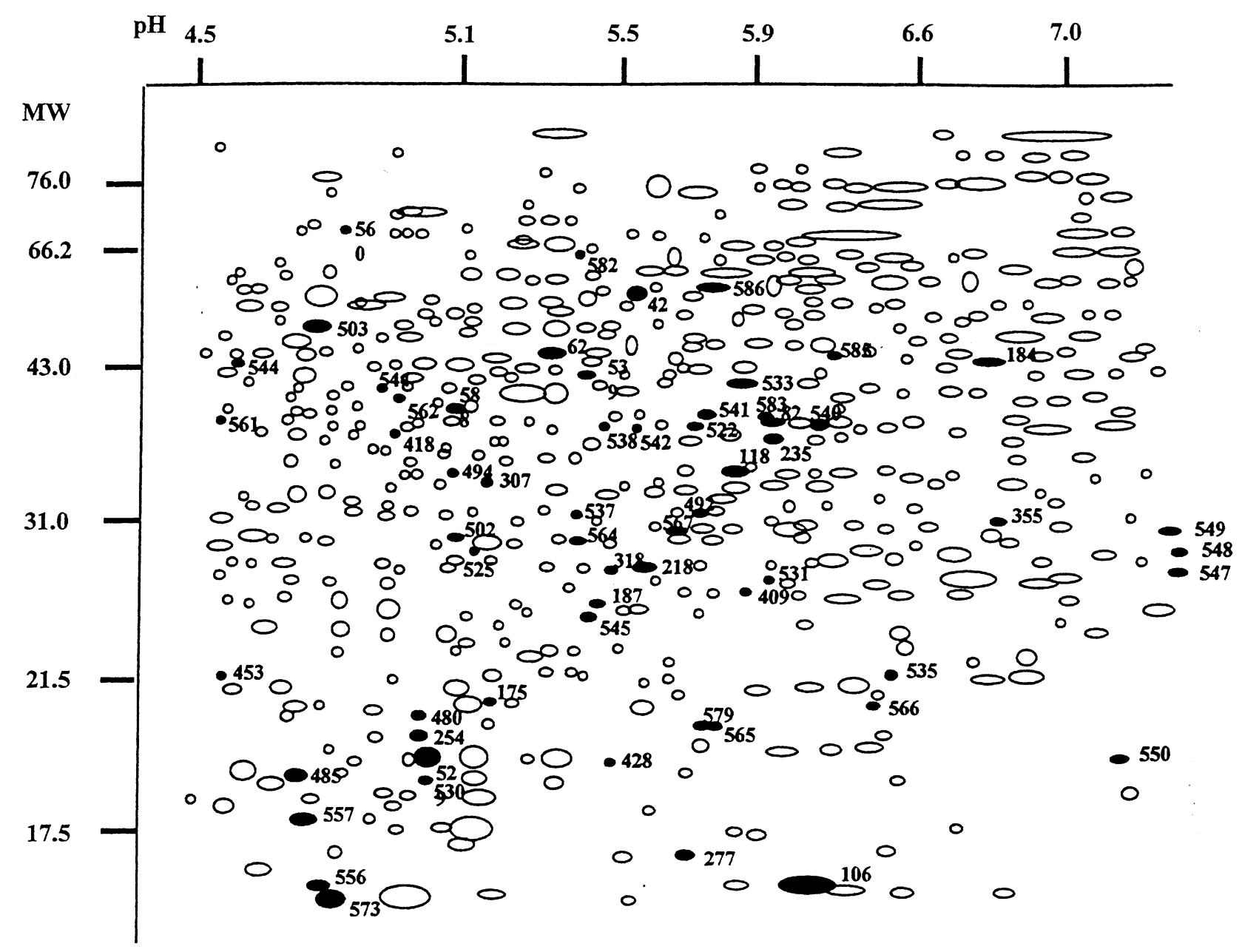

Fig. 4 Master image obtained after 2-DGE analysis of the European and Peruvian Globodera pallida populations. Black spots represent spots listed in Table 3 with their master numbers.

ted in the European populations, was present in two populations of each Peruvian pathotype.

The mean genetic distance in the Peruvian populations was 0.39 [0.23-0.50] whereas the mean genetic distance in the European populations was 0.45 [0.29-0.61]. The mean genetic distance between the two groups was 0.53 [0.42-0.59] (Table 4(a)). The consensus tree (Fig. 5A) derived from the genetic distances shows that the European and Peruvian populations can clearly be separated and that this clustering is supported by strong bootstrap values. In the Peruvian group, two pairs of populations were observed with bootstrap values above 96 (P4A 6 and P4A 1, P6A 14 and P6A 15). In the European group, two pairs of populations were also found: (Saint Malo, Pas de Calais) and (Perpignan, BB1), with respective bootstrap values of 84 and 79 .

\section{RAPD fingerprinting}

An average of 25 markers per primer combination was observed in a size range between 225 and $3000 \mathrm{bp}$, and 180 polymorphic markers were retained for the analysis. Clearly the Peruvian populations are closer to themselves than to those from Europe (Table 4(b)). The mean genetic distance in the Peruvian populations was 0.41 [0.12-0.57] whereas the mean genetic distance in the European populations was $0.25[0.10-0.40]$. The mean genetic distance between the two groups was 0.57 [0.330.58]. The P5A 8 population seems intermediate between the Peruvian and European populations. If this population is removed from the analysis, the genetic distance between the two groups increases from 0.57 to 0.59 . Similarly the genetic distance within the Peruvian group drops from 0.41 to 0.38 . With this set of populations 


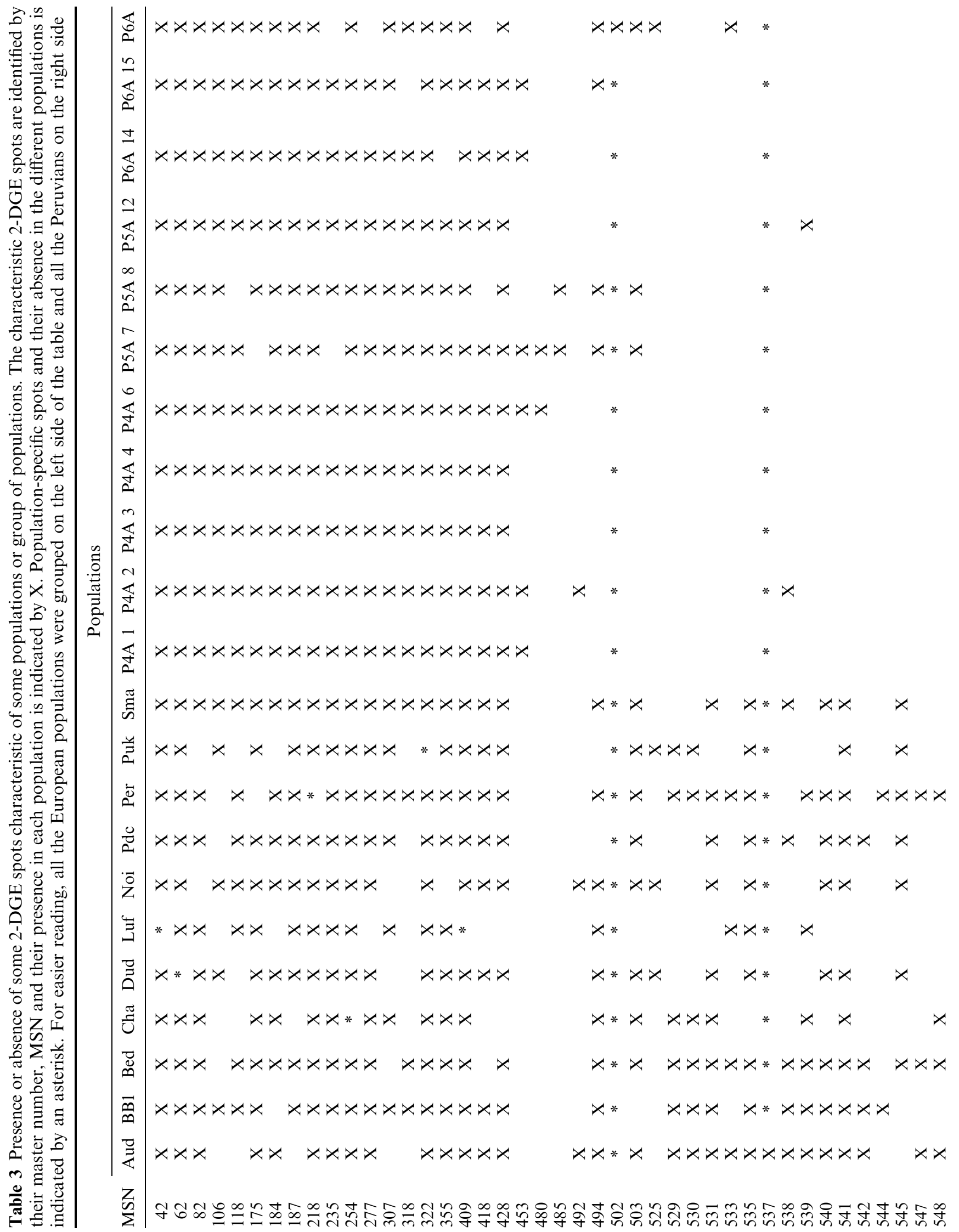

(c) The Genetics Society of Great Britain, Heredity, 86, 277-290. 


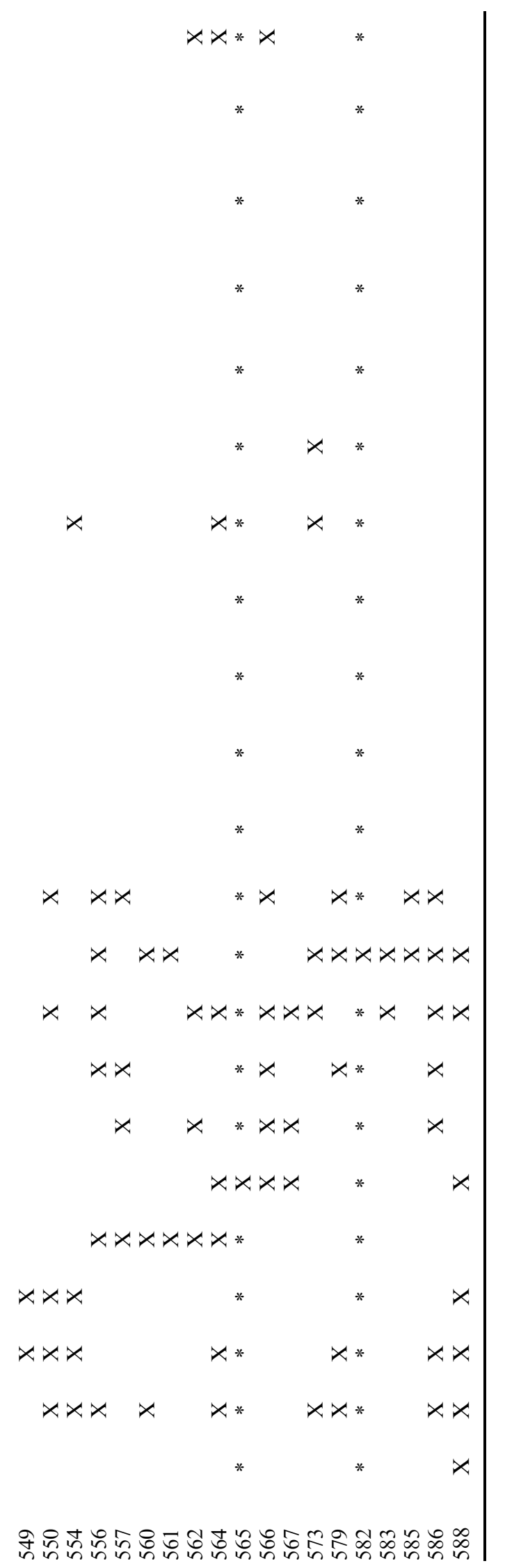

there are two groups with a higher diversity within the Peruvian group than within the European one.

The tree shown in Fig. 5B clearly separates the Peruvian and European populations. In the Peruvian populations, the clusters are in relative good accordance with the pathotype scheme of Canto \& Scurrah (1977) who separated the P4A pathotype from the others. In contrast, the European populations cluster independently of the pathotype scheme. The $\mathrm{Pa} 1$ and $\mathrm{Pa} 2$ pathotypes cluster within a group of $\mathrm{Pa} 2 / 3$ pathotypes. The Luffness population, which is supposed to be different (Phillips et al., 1992; Phillips \& Trudgill, 1998), is not clearly distinct from other European populations.

\section{Discussion}

Two repeated DNA sequences, representing two different satellite DNA families from European and Peruvian G. pallida, were isolated. While no substantial similarities were detected between the $A l u \mathrm{I}$ sequences and any other sequence recorded in the GenBank and EMBL database, the SmaI sequences belong undoubtedly to the same satellite DNA family as that isolated by Burrows et al. (1995) using the HindIII enzyme. The average divergence from the consensus sequence is estimated at only $1.7 \%$ for the $S m a \mathrm{I}$ family and $5.5 \%$ for the $A l u \mathrm{I}$ family. Compared with other satellite DNAs, the SmaI family seems to be extremely conserved. Such a high degree of sequence similarity was shown for satellite DNAs of meiotic parthenogenetic nematodes like Meloidogyne fallax (2.7\%) (Castagnone et al., 1998) and M. hapla (3\%) (Piotte et al., 1994). Two explanations can be provided: (i) the $S m a$ I satellite DNA family is younger than the $A l u \mathrm{I}$ family; and (ii) the impact of the homogenizing process is stronger in the SmaI family. It has been suggested that during the evolution of satellite DNAs, $\mathrm{C}$ to $\mathrm{T}$ and $\mathrm{G}$ to $\mathrm{A}$ transitions are more frequent than the reverse transitions, which results in $\mathrm{A}+\mathrm{T}$ enrichment of these sequences (Ugarkovic et al., 1989). Under this hypothesis, the low $\mathrm{A}+\mathrm{T}$ content observed within the $A l u \mathrm{I}$ satellite DNA family is not in accordance with the first explanation while the observation of a higher number of multivariant positions substituted with the same nucleotide in the SmaI family is in accordance with the second explanation.

Satellite DNAs that evolve in a concerted manner are often described as species-specific sequences but some may be restricted to a specific group of related species (Mantovani et al., 1997; Mestrovic et al., 1998). This seems to be the case with the isolated $A l u \mathrm{I}$ satellite DNA, which recognizes both G. pallida and 'G. mexicana', two closely related species that cluster together in our ITS analysis. Though not intense, the consistent 


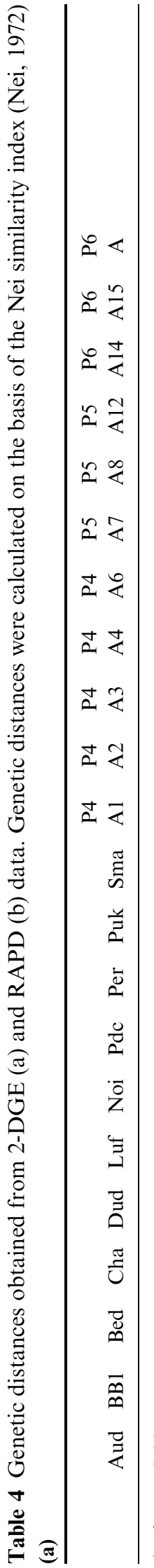

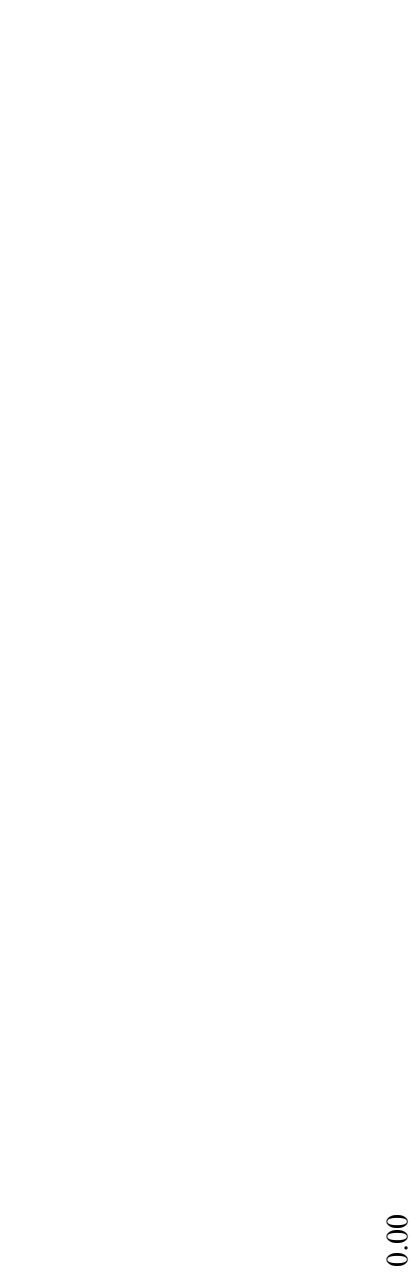

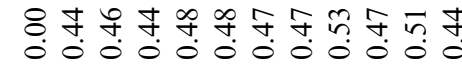

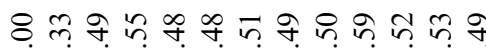
0000000000000

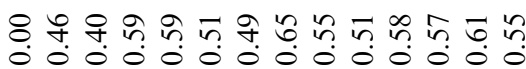

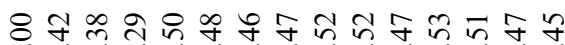
000000000000000

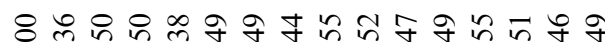
0000000000000000 \& 8 주요

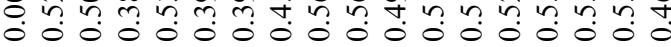

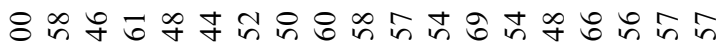

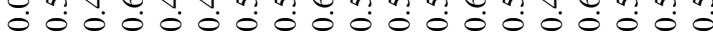

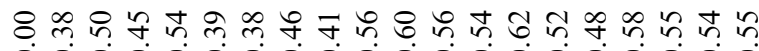
00000000000000000000

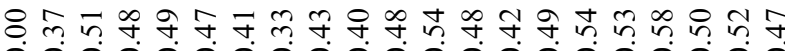

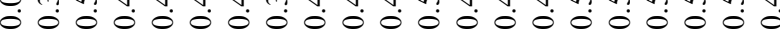
४ Ұ 0000000000000000000000

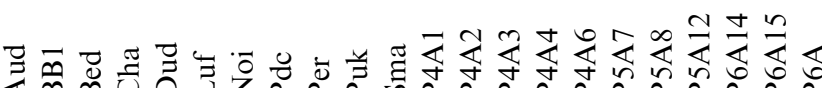

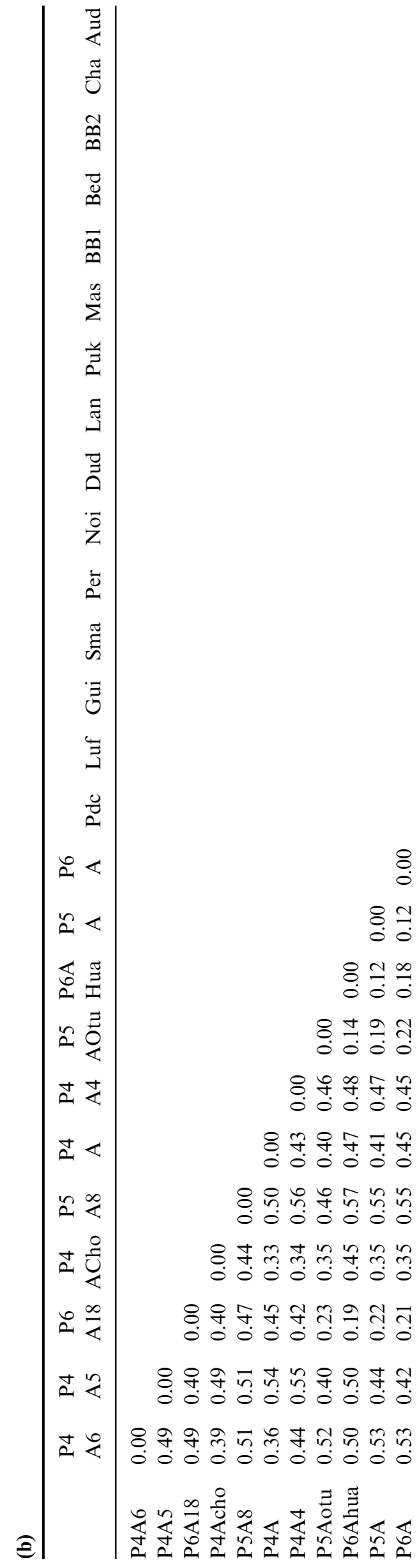




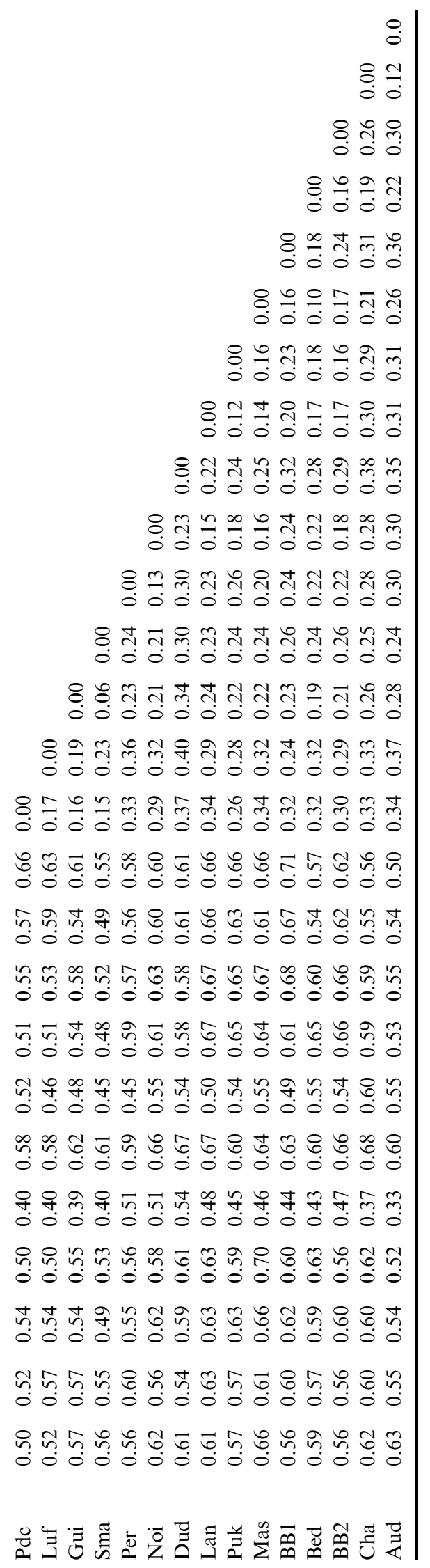

hybridization of both probes to the same subset of G. tabacum populations, all classified as G. t. virginiae, was confirmed in a more extensive dot blot (data not shown). This result gives some support to the subspecies grouping adopted inside the G. tabacum group but raises questions about the possible relationships which exist between some G. tabacum populations and the G. pallida and 'G. mexicana' species.

The Peruvian populations are more complex. Their ITS heterogeneity is shown to be greater than that observed between populations inside each of the other groups (Thiéry \& Mugniéry, 1996). Blok et al. (1998) showed little sequence variation between repeat units of the rDNA of a P5A population compared to a P4A population and one can notice that this last pathotype appears also more variable in our ITS analysis. Moreover, it is tempting to speculate that some of the Peruvian populations are mixtures of individuals with different types of rDNA or even that different types of repeat units occur in the rDNA of an individual, as it was shown to be the case in some imported populations of G. pallida (Blok et al., 1998). ITS-RFLP and satellite DNA sequences are used as taxonomic markers for nematodes (Grenier et al., 1997; Powers et al., 1997). However, the expected clarification of the taxonomic status of the Peruvian populations is still far from being obtained. Although the SmaI satellite DNA groups the Peruvian and the European G. pallida, the Peruvian populations appear to be distinct from all the other species and especially from the European G. pallida in the ITS-RFLP analysis. On one hand, we know that satellite DNA can be unable to distinguish closely related species (Castagnone et al., 1998) but, on the other hand, because of the low number of unambiguous markers revealed by the ITS-RFLP analysis, the robustness of the tree inferred from these data is not well supported. In fact, only 44 markers were found in this study, but this number would have dropped drastically to 26 or even to 22 if, respectively, G. artemisiae or both of the non PCN species ( $G$. artemisiae and G. tabacum) had not been included. If the ITS region is a good candidate for species determination, then including the Peruvian populations in G. pallida would be questionable. Our results emphasize the need to augment these molecular data with biological and morphological studies before addressing the exact taxonomic position of these Peruvian populations.

Two independent data sets were used to determine the intraspecific variation among European and South American G. pallida populations: both 2-DGE and RAPD analysis confirm the clear distinction between the Peruvian and the European populations. With RAPD the P5A 8 population is the only one to be somewhat intermediate, although it belongs clearly to the Peruvian group when analysed by ITS-RFLP. The same type of 

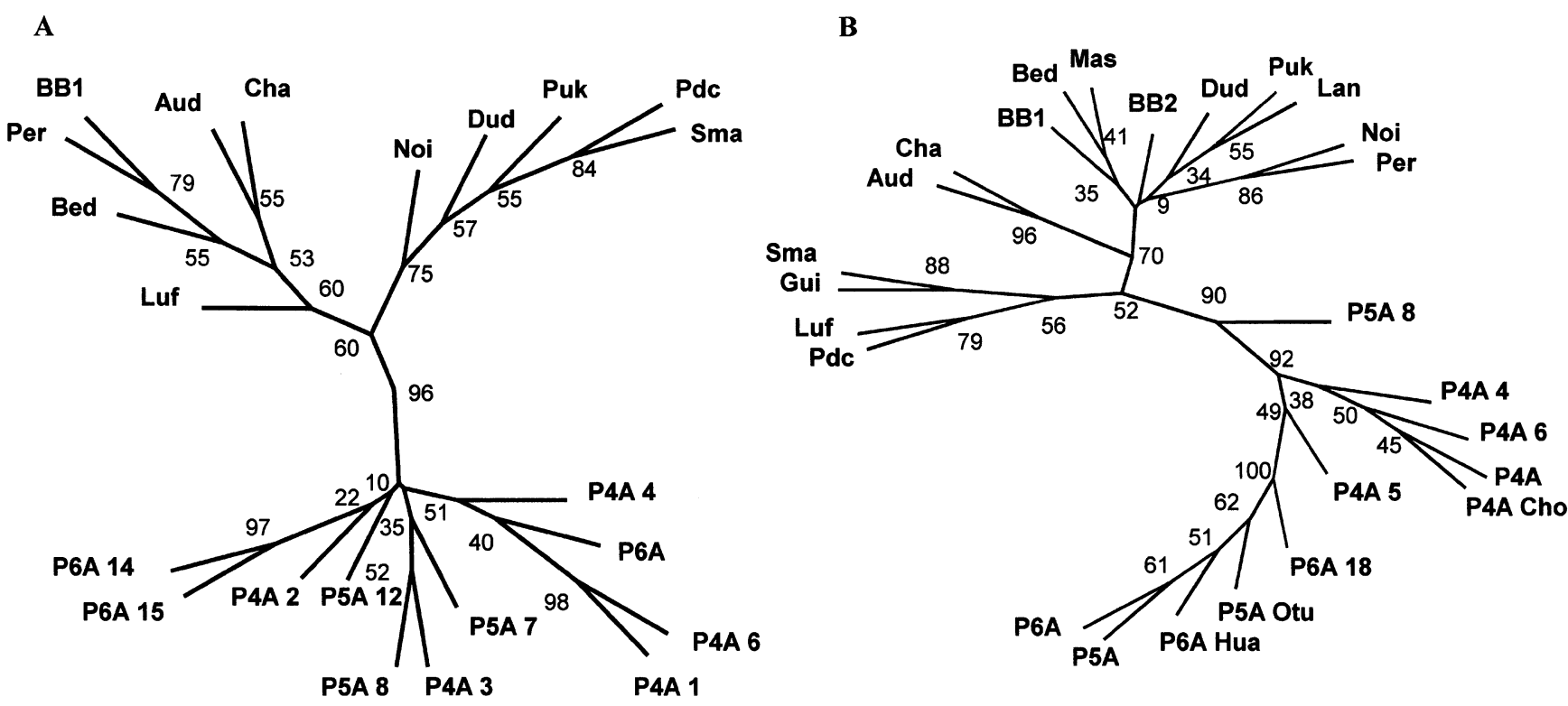

Fig. 5 Unrooted boot-strapped trees of the European and Peruvian Globodera pallida populations estimated by Neighbour Joining from the 2-DGE (A) and RAPD (B) genetic distances presented in Table 4. Bootstrap values obtained after 500 iterations are indicated beside each branch.

South American/European clustering was observed by Blok et al. (1997) who found, using RAPDs with a set of two Peruvian and 17 British G. pallida populations, an average similarity of $51.8 \%$ between these two groups. Our mean RAPD and 2-DGE genetic distances can also be compared to those reported in Folkertsma et al. (1996a) on a set of 36 European G. pallida field populations. While RAPD genetic distances are similar, our 2-DGE distances are higher. We have scored a large number of faint spots which undoubtedly have tended to increase the protein variability. Our 2-DGE genetic distances are also probably overestimated due to some artefacts of the technique, particularly the failure to detect very faint spots on some gels. It would have been possible to eliminate these faint spots, but we have preferred to keep all the detected and modelled spots in the patterns because some of them were scored in all the populations. In addition to and in contrast to the 2-DGE data of Folkertsma et al. (1996a), we chose to consider all the proteins as independent markers, although some are probably produced by alleles at polymorphic loci.

Inside each group, no clear correlation between pathotype is evident. The Pal pathotype (the Duddingston population) clusters within the $\mathrm{Pa} 2$ and $\mathrm{Pa} 2 / 3$ pathotypes. While 2-DGE associates the Peruvian populations in a way that does not reflect the virulence groups, the RAPD data show that a P4A and a P5A/ P6A groupings tend to be observed. This difference is expected, as, biologically, the P4A pathotype differs strongly from the P5A and the P6A pathotypes by its inability to develop on Solanum vernei $\left(\mathrm{VT}^{\mathrm{n}}\right)^{2} 62.33 .3$ (Canto \& Scurrah, 1977; Phillips \& Trudgill, 1998). However, as the Pal pathotype also differs from the $\mathrm{Pa} 2 / 3$ pathotype by its inability to develop on the $H 2$ gene from S. multidissectum P55/7 (Kort et al., 1977) the same type of difference would also be expected for the European Duddingston population, but was not found. Some pairs of populations appear to be closely related. These populations might have the same origin, with the same founders, but more probably are the result of secondary founding events. The slight differences observed between each member of a pair could be explained by the reduction of the diversity associated to the founder effect and also by occurrence of subsequent random genetic drift.

Apart from the Peruvian/European distinction, considerable discrepancies are observed between the trees obtained by 2-DGE and RAPD. Folkertsma et al. (1996a) did a comparison of the two techniques with a same set of G. pallida populations; they reported such inconsistencies and concluded that when clusters of populations are not well differentiated from each other, different types of data set may result in clusters with differing compositions. In our case, the results obtained are surprising in that if one assumes that the European populations were imported from the Andean region, it would be expected that the variability in the South American populations would be greater than the variability in the European populations. RAPD data reveal, 
in the Peruvian group, high genetic distances and a completely unresolved branching, consistent with this great variability. However, 2-DGE data reveal high genetic distances in the European populations and several characteristic proteins are observed in these populations. If we assume that the European populations were introduced from other South American populations that were not investigated in this study, then the characteristic proteins observed can be explained. Why RAPD and 2-DGE display opposite results concerning the most variable group remains to be further investigated. But, the codominant nature of 2-DGE markers, in contrast to the usual dominant nature of RAPD markers, can be part of the explanation. Assuming that very few nematodes were at the origin of the primary founders of the European populations and that the genetic drift has resulted in the fixing of different alleles in these imported populations, it is possible that our inability to identify products of alleles at polymorphic loci has led to an overestimation of the genetic distances by 2-DGE in the European group.

The European populations seem therefore to have come from a different part of the Peruvian area than that investigated in this study. The PCN samples in this study may not be representative of the whole of Peru. Further samples, both of Peruvian PCN populations and of other South American populations such as Bolivian and Chilean populations, may reveal the origin of European PCN.

\section{Acknowledgements}

We are grateful to Dr D. Sturhan and Dr M. Scurrah for providing us with G. artemisiae and the Peruvian populations, respectively.

\section{References}

BAKKER, J., FOLKERTSMA, R. T., ROUPPE VAN DER VOORT, J. N., DE BOER, J. M. ET AL. 1993. Changing concepts and molecular approaches in the management of virulence genes in potato cyst nematodes. Ann. Rev. Phytopath., 31, 169-190.

BENDEZU, I. F., EVANS, K., BURROWS, P. R., DE POMERAI, D. ET $A L$. 1998. Inter- and intra-specific genomic variability of the potato cyst nematodes Globodera pallida and G. rostochiensis from Europe and South America using RAPD-PCR. Nematologica, 44, 49-61.

BLOK, V. C., PHILlips, M. S. AND HARROWER, B. E. 1997. Comparison of British populations of potato cyst nematodes with populations from continental Europe and South America using RAPDs. Genome, 40, 286-293.

BLOK, V. C., MALlOCH, G., HARROWER, B. E., PHILliPS, M. S. ET $A L$. 1998. Intraspecific variation in ribosomal DNA in populations of the potato cyst nematode Globodera pallida. J. Nematol., 30, 262-274.
BOSSIS, M. AND MUGNIÉRY, D. 1993. Specific status of six Globodera parasites of solanaceous plants studied by means of two-dimensional gel electrophoresis with comparison of gel patterns by a computed system. Fund. Appl. Nematol., 16, 47-56.

BURROWS, P. R., SMOKER, M. AND GRISI, M. E. 1995. Sequence and genomic organisation of a novel repetitive DNA element from the potato cyst nematode Globodera pallida. Mol. Biochem. Parasitol., 73, 245-248.

CANTO, M. AND DE SCURRAH, M. M. 1977. Races of the potato cyst nematode in the Andean region and a new system of classification. Nematologica, 23, 340-349.

CASTAGNONE-SERENO, P., SEMBLAT, J.-P., LEROY, F. AND ABAD, P. 1998. A new Alu I satellite DNA in the root-knot nematode Meloidogyne fallax: relationships with satellites from the sympatric species M. hapla and M. chitwoodi. Mol. Biol. Evol., 15, 1115-1122.

EVANS, K. AND STONE, A. R. 1977. A review of the distribution and biology of the potato cyst nematodes Globodera rostochiensis and G. pallida. PANS Bull., 23, 417-430.

EVANS, K., FRANCO, J. AND DE SCURRAH, M. M. 1975. Distribution of species of potato cyst nematodes in South America. Nematologica, 21, 365-369.

FELSENSTEIN, J. 1993. PHYLIP (Phylogeny Inference Package), version 3.5.c. University of Washington, Seattle.

FOLKERTSMA, R. T., DE GROOT, K. E., VAN KOERT, P. H., VAN GENTPELZER, M. P. ET AL. 1996a. Cluster analysis of 36 Globodera pallida field populations using two sets of molecular markers. Eur. J. Plant Pathol., 102, 577-584.

FOLKERTSMA, R.T., ROUPPE VAN DER VOORT, J. N., DE GROOT, K. E., VAN ZANDVOORT, P. M. ET AL. 1996b. Gene pool similarities of potato cyst nematode populations assessed by AFLP analysis. Mol. Plant-Microbe Interact., 9, 47-54.

GRENIER, E., CASTAGNONE-SERENO, P. AND ABAD, P. 1997. Satellite DNA sequences as taxonomic markers in nematodes of agronomic interest. Parasitol. Today, 13, 398-401.

HOCHSTRASSER, D. F., PATCHORNIK, A. AND MERRIL, C. R. 1988. Development of polyacrylamide gels that improve the separation of proteins and their detection by silver staining. Analyt. Biochem., 173, 412-423.

KORT, J., ROSS, H., RUMPENHORST, H. J. AND STONE, A. R. 1977. An international scheme for identifying and classifying pathotypes of potato cyst-nematodes Globodera rostochiensis and G. pallida. Nematologica, 23, 333-339.

MANTOVANI, B., TINTI, F., BACHMANN, L. AND SCALI, V. 1997. The Bag320 satellite DNA family in Bacillus stick insects (Phasmatodea): Different rates of molecular evolution of highly repetitive DNA in bisexual and parthenogenetic taxa. Mol. Biol. Evol., 14, 1197-1205.

MESTROVIC, N., PLOHL, M., MrAvinAC, B. AND UGARKovic, D. 1998. Evolution of satellite DNAs from the genus Palorus Experimental evidence for the "library" hypothesis. Mol. Biol. Evol., 15, 1062-1068.

MUGNIÉRY, D., PHILLIPS, M. S., RUMPENHORST, H. J., STONE, A. R. ET AL. 1989. Assessment of partial resistance of potato to, and pathotype and virulence differences in, potato cyst nematodes. EPPO Bull., 19, 7-25.

NEI, M. 1972. Genetic distances between populations. Am. Nat., 106, 283-292. 
O'FARrell, P. H. 1975. High resolution two-dimensional electrophoresis of proteins. J. Biol. Chem., 250, 4007-4021.

OAKLEY, B. R., KIRSCH, D. R. AND MORRIS, N. R. 1980. A simplified ultrasensitive silver stain for detecting proteins in polyacrylamide gels. Analyt. Biochem., 105, 361-363.

PHILLIPS, M. S. AND TRUDGILL, D. L. 1983. Variations in the ability of Globodera pallida to produce females on potato clones bred from Solanum vernei or $S$. tuberosum ssp. andigena CPC2802. Nematologica, 29, 217-226.

PHILliPS, M. S. AND TRUDGILL, D. L. 1998. Variation of virulence, in terms of quantitative reproduction of Globodera pallida populations, from Europe and South America, in relation to resistance from Solanum vernei and S. tuberosum ssp. andigena CPC 2802. Nematologica, 44, 409-423.

PHILliPS, M. S., HARROWER, B. E., TRUDGILl, D. L., CATLEY, M. A. $E T A L$. 1992. Genetic variation in British populations of Globodera pallida as revealed by isozyme and DNA analyses. Nematologica, 38, 304-319.

PIOTTE, C., CASTAGNONE-SERENO, P., BONGIOVANNI, M., DALMASSO, A. ET AL. 1994. Cloning and characterization of two satellite DNAs in the low-C-value genome of the nematode Meloidogyne spp. Gene, 138, 175-180.

POWERS, T. O., TODD, T. C., BURNELl, A. M., MURRAY, P. C., FLEMING, C. C. ET AL. 1997. The rDNA Internal Transcribed
Spacer region as a taxonomic marker for nematodes. J. Nematol., 29, 441-450.

SAMBROOK, J., FRITSCH, E. F. AND MANIATIS, T. 1989. Molecular Cloning: a Laboratory Manual, 2nd edn. Cold Spring Harbor, NY.

THIÉRY, M. AND MUGNIÉRY, D. 1996. Interspecific spacers rDNA restriction fragment length polymorphism in Globodera species, parasites of Solanaceous plants. Fund. Appl. Nematol., 19, 471-479.

THIÉRY, M., FOUVILLE, D. AND MUGNIÉRY, D. 1997. Intra- and interspecific variability in Globodera, parasites of Solanaceous plants, revealed by Random Amplified Polymorphic DNA (RAPD) and correlation with biological features. Fund. Appl. Nematol., 20, 495-504.

UGARKovic, D., PLOHL, M. AND GAMUlin, v. 1989. Sequence variability of satellite DNA from the mealworm Tenebrio molitor. Gene, 83, 181-183.

VRAIN, T. C., WAKARCHUK, D. A., LEVESQUE, A. C. AND HAMILTON, R. I. 1992. Interspecific rDNA restriction length polymorphism in the Xiphinema americanum group. Fund. Appl. Nematol., 15, 563-573.

zIVY, M. 1990. Une nouvelle méthode de détection des spots d'électrophorèse bidimensionnelle des protéines. 8ème congr. soc. électrophorèse, Lyon. 